\title{
A Critical Analysis of Advertising Bombardment in Today's World
}

\author{
Samson Ademagba Sambe \\ Department of Mass Communication Benue State University, P.M.B 102119, Makurdi
}

\begin{abstract}
Advertising, a big business in itself, is the engine that allows the rest of the business world to flourish. It has the subtle ability to reach out and touch everyone living and working in the modern world. Largely, it does this through the usual media of mass communication, but lately it also uses an increasing variety of unusual means to find its audience. Today, a concentrated outpouring of advertisements is directed at the consciousness of consumer's every day, through traditional and non-traditional outlets. Accordingly, this investigation examines the proliferation and preponderance of advertising in contemporary living. Among other things, it recommends that the Advertising Practitioners' Council of Nigeria (APCON) should be empowered to regulate the exposure of advertisements to audiences.
\end{abstract}

\section{Introduction}

Consumers in the current information seeking society are beset by an array of advertising messages. Wherever they go, wherever they turn, customers are overwhelmed with a barrage of advertisements bordering on harassment. Indoors and outdoors, people are surrounded by commercial announcements, notices, displays, handbills, placards, posters etc. Advertising introduces the man with the goods, services or ideas to the man in need of the goods, services or ideas.

Advertising professionals are eager to get their information noticed. Everywhere one looks - shopping carts, DVDs, blimps, car bumper stickers, T-shirts, locker posters, Internet, the conventional mass media of newspapers, magazines, radio, television and billboards - someone is trying to sell something. According to Ginn (1995, p. 222), "in one high school, an Australian teenager even rents his head for advertising space, shaving an advertisement into his hair each week."

In advertising, as in communication in general, noise hinders the consumer's reception of the message. Wells, Moriarty \& Burnett (2006, p.564) define noise as "anything that interferes with or distorts the advertising message's delivery to the target audience." According to them, on a micro level, external noise could be as simple as bad radio or television reception, but a more important factor is clutter, which, they say, is the multitude of messages all competing to get consumers' attention. They explain that more specifically, it is all the advertisements that audiences watch on television and see in print media, as well as in unexpected places, such as in imprints on the sand on the beach. The authors observe that the massive number of advertisements makes it harder and harder for any one advertisement to get the attention of its audience.

People use many techniques to avoid clutter and information overload. They filter messages they don't want to see, such as turning the page, switching the channel, hitting the mute button, tossing unopened mail that looks like an advertisement and deleting spam without looking at it. Other avoidance techniques such as e-mail filters, "no-call" laws, and direct TV that skips commercials are creating new dilemmas for marketers. According to Wells, Moriarty \& Burnett (2006), many marketers are experiencing lower response rates to their campaigns as a result of filters and other avoidance techniques.

\section{Conceptual Clarifications:}

Advertising:

Today, definitions of advertising abound. Journalists, for example, might define it as a persuasion process; business people see it as a marketing process; economists and sociologists tend to focus on its economic, societal or ethical significances, and some consumers might define it simply as a nuisance. Each of these perspectives has some merit.

According to Agee et al $(1982 ;$ p. 247) "advertising finds its roots back to the Latin verb for 'giving attention'. Accordingly, it means 'getting attention" or better, "the attempt to secure public attention for commercial reasons". That attempt is open, unconcealed, and involves bought-and-paid-for exposition.

Ginn (1995, p. 222) observes that "an advertisement has just one purpose - to sell something." It may be selling a product (cereal advertisement), a service (house-painting advertisement), an idea (public service advertisement against drug abuse), or a person (political advertisement). 
Arens, Weigold and Arens (2008, p. 7) define advertising as "the structured and composed, nonpersonal communication of information, usually paid for and usually persuasive in nature, about products (goods, services and ideas) by identified sponsors through various media."

Firstly, advertising is a very structured form of applied communication, employing both verbal and non verbal elements that are composed to fill specific space (newspaper, magazine, billboard etc) and time formats (radio, television) determined by the sponsor.

Secondly, advertising is typically directed to groups of people rather than to individuals. It is therefore non personal, or mass, communication. These people could be consumers who buy products like Macleans toothpaste for their personal use or they might be business people who buy fleet of cars for commercial or government use.

Thirdly, most advertising is paid for by sponsors. Coca Cola, for example, pays the newspaper or the radio or television station to carry the advertisements consumers read, hear or watch. But some sponsors do not pay for their advertisements. The Red Cross Society and the Cancer Society are among the many national organisations in the United States whose public service messages are carried at no charge because of their nonprofit status.

Of course, most advertising is intended to be persuasive - to win converts to a product, service or idea. Some advertisements, such as legal announcements, are intended merely to inform, not to persuade, but they are still advertisements because they satisfy all the other requirements of this definition.

In addition to promoting tangible goods such as oranges and olive oil, advertising helps publicise the intangible services of bankers, beauticians, bicycle repair shops, bill collectors and telephone companies. Increasingly, advertising is used to advocate a wide variety of ideas, whether economic, political, religious or social.

An advertisement identifies its sponsor. This seems obvious. The sponsor wants to be named, or why pay to advertise?

Finally, advertising reaches consumers through a channel of communication referred to as a medium. An advertising medium is any paid means used to present an advertisement to its target audience. Thus, we have radio advertisement (or better still, commercial), television advertisement (commercial), newspaper advertisements, and so on. When a child tells somebody how sweet the latest ice cream looks and tastes, that is sometimes called word-of-mouth (WOM) advertising. Although WOM is a communication medium, it is not an advertising medium. It is not structured or openly sponsored or paid for.

According to Arens, Weigold and Arens (2008, p. 94), advertising is justified by the abundance principle: This means that in an economy that produces more goods and services that can be consumed, advertising gives consumers more complete information about the choices available to them, encourages more sellers to compete more effectively and thereby serves the self-interest of both consumers and marketers.

\section{Bombardment}

Of the four meanings given by the American Heritage Dictionary of the English Language (2000, p. 208), the one that refers to the context in which the word "bombardment" is used here is "to assail persistently, as with requests "(read: "as with advertising"). Accordingly, audiences or consumers bombarded with advertisements are flooded with steady messages about products, services or ideas, in order to get their attention and provide them with information. And this is all in an attempt to create some kind of response, such as a sale, a change in attitude or a strengthening of a belief from them.

\section{A Survey of Advertising}

Hanson (2005, p. 318) explains that advertisements are paid messages about an organisation, product, service or idea that appear in the mass media. According to him, advertising provides numerous benefits to the society, including making media less expensive and contributing to a large and diverse economy. He further says while advertising has existed in the United States since colonial times, it was industrialisation, urbanisation and the growth of national transportation networks in the $19^{\text {th }}$ century that allowed it to become a major industry. Advertising transformed the media industry from one supported primarily by subscribers to one supported by advertising revenues. Publishers (and later broadcasters) were no longer sellers of content to audience members; they were now sellers of audiences to advertisers.

Azzaro (2004:1) says total 2003 advertising spending in the United States was almost \$249 billion. According to Wells, Moriarty and Burnett (2006:13) "In 2002-2003 advertising agency gross income was \$10.6 billion worldwide"; the authors further revealed that the top three U.S advertising agencies were J. Walter Thompson, Leo Burnett, and McCann-Erickson Worldwide. According to them, Japanese-based Dentsu, Inc. is the largest agency in the world. 
The authors list the world's top ten advertising agencies thus:

Table 1: World's Top Ten Advertising Agencies, 2003

\begin{tabular}{|c|c|c|c|}
\hline Rank & Agency & Headquarters & $\begin{array}{c}\text { Worldwide Gross } \\
\text { Income }\end{array}$ \\
\hline 1. & Dentsu & Tokyo & $\$ 1,864.1$ \\
\hline 2. & BBDO Worldwide & New York & $1,237.5$ \\
\hline 3. & McCann-Erickson Worldwide & New York & $1,220.1$ \\
\hline 4. & J. Walter Thompson Inc & New York & $1,178.5$ \\
\hline 5. & Publicis Worldwide & Paris & $1,066.0$ \\
\hline 6. & DDB Worldwide Communications & New York & $1,214.6$ \\
\hline 7. & Leo Burnett Worldwide & Chicago & $1,072.3$ \\
\hline 8. & TBWA Worldwide & New York & 771.0 \\
\hline 9. & Euro RSCG Worldwide & New York & 756.1 \\
\hline 10. & Ogilvy \& Mather Worldwide & New York & $1,135.4$ \\
\hline
\end{tabular}

Source: Wells, Moriarty \& Burnett (2006)

Nigeria's THISDAY newspaper says there are close to one hundred registered advertising agencies in the country today, with many of them having built many brands considered strong from the scratch. The daily publication ranked the first twelve as follows:

Table 2: Nigeria's Top 12 Advertising Agencies

\begin{tabular}{|c|c|c|c|c|c|}
\hline $\mathbf{S} / \mathbf{N}$ & Agency & Name of the CEO & 3 Major Accounts & Billings & $\begin{array}{c}\text { Staff } \\
\text { strength }\end{array}$ \\
\hline 1. & Insight & Mr. Jimi Awosika & $\begin{array}{c}\text { Nigerian Breweries, } \\
\text { Seven-Up Plc, Bank } \\
\text { PHB }\end{array}$ & $\begin{array}{l}\text { Between four and } \\
\text { five billion Naira } \\
\text { range }\end{array}$ & $100+$ \\
\hline 2. & DDB & Mr. Enyi Odigbo & $\begin{array}{l}\text { MTN, Fidelity Bank, } \\
\text { Mimee Noodles }\end{array}$ & $\begin{array}{l}\text { Over four billion } \\
\text { Naira }\end{array}$ & 85 \\
\hline 3. & Centrespread & Mr. Kola Ayanwale & $\begin{array}{c}\text { Sky Bank, } \\
\text { Zenith Bank, } \\
\text { Starcomms }\end{array}$ & $\begin{array}{l}\text { Within one billion } \\
\text { Naira range }\end{array}$ & 77 \\
\hline 4. & SO \& U & Mr. Udeme Ufot & $\begin{array}{c}\text { Guiness, } \\
\text { Access Bank, } \\
\text { Procter \& Gamble }\end{array}$ & $\begin{array}{l}\text { Within one billion } \\
\text { range }\end{array}$ & 70 \\
\hline 5. & Prima Garnet & Mr. Lolu Akinwunmi & $\begin{array}{c}\text { Coca-Cola, } \\
\text { Shell, Multichoice }\end{array}$ & $\begin{array}{l}\text { Over three billion } \\
\text { Naira range }\end{array}$ & 75 \\
\hline 6. & Rosabel & Mr. Tunji Abioye & $\begin{array}{l}\text { United Bank for Africa, } \\
\text { Grand Oak, Toyota }\end{array}$ & $\begin{array}{l}\text { Within one billion } \\
\text { Naira range }\end{array}$ & 80 \\
\hline 7. & $\begin{array}{c}\text { TBWA/ } \\
\text { CONCEPT }\end{array}$ & Mr. Kelechi Nwosu & $\begin{array}{l}\text { UAC, Stanbic IBTC, } \\
\text { Indomie }\end{array}$ & $\begin{array}{l}\text { Within one billion } \\
\text { Naira range }\end{array}$ & 50 \\
\hline 8. & Lintas & Mr. Erhabor Emokpae & $\begin{array}{l}\text { Star Lager Beer, } \\
\text { Maltina, Unilever }\end{array}$ & (not given) & $75+$ \\
\hline 9. & LTC/JWT & (not given) & Nokia, Shell & (not given) & (not given) \\
\hline 10. & Bate Cosse & Mr. Funmi Onabolu & $\begin{array}{l}\text { Interswitch, } \\
\text { Wema Bank, } \\
\text { Virgin Nig. }\end{array}$ & (not given) & 56 \\
\hline 11. & 141 Worldwide & Mr. Bunmi Oke & $\begin{array}{l}\text { BAT, Etisalat, } \\
\text { Virgin Atlantic }\end{array}$ & (not given) & $\begin{array}{l}\text { (not } \\
\text { given) }\end{array}$ \\
\hline 12. & STB McCann & Mr. Rufai Ladipo & $\begin{array}{l}\text { Western Union, } \\
\text { UBA, Peugeot }\end{array}$ & (not given) & 80 \\
\hline
\end{tabular}

Source: THISDAY newspaper, Sunday, Feb. 15, 2009

Indeed, advertising is the principal source of revenue that supports the media system. This dependence creates a problem between the public's preferences (to get timely reports and programmes that inform, educate and entertain), and the criteria employed by the media managers (selling the audiences to advertisers). People, as consumers of communication, judge it by its value and meaning to them. However, advertisers judge it by its efficiency in disseminating what they call "exposure opportunities".

Thus, media content has been driven primarily by the need to maximise audiences for sale rather than by the desire to communicate the truth about our world or express deep thoughts and feelings.

To Okunna (1994:30), the relationship between the world of commerce (advertisers) and the mass media is a symbiotic one, for two reasons. Firstly, advertisers need the mass media to sell their products. An advertising message needs to be transmitted through a medium capable of reaching every member of a target audience and the mass media provide such a medium. Secondly, the mass media need advertising revenues to stay buoyant. In the case of private commercial media, advertising revenue is fundamental to the media staying alive. 
Dominick (2002:378) says advertising fulfils four basic functions in society.

1. It serves a marketing function by helping companies that provide products or services sell their products. Personal selling, sales promotions and advertising work together to help market the product.

2. Advertising is educational. People learn about new products and services or improvements in existing ones through advertising.

3. Advertising plays an economic role. The ability to advertise allows new competitors to enter the business area eg MTN as a rival to NITEL, in the telecommunication industry in Nigeria, or Guaranty Trust Bank (GTB), a new generation bank, as a competitor to First Bank Nigeria (FBN) Limited, the oldest bank in the country established since 1894. Competition, in turn, encourages product improvements and can lead to lower prices. Moreover, advertising reaches a mass audience, thus greatly reducing the cost of personal selling and distribution.

4. Advertising performs a definite social function. By vividly displaying the material and cultural opportunities available in a free-enterprises society, advertising helps increase productivity and raises the standard of living.

Advertising helps create the mass market necessary for mass production and allows for the diffusion of a wide variety of innovations. It enables the establishment of brand names sold nationally and internationally (eg, Coca-Cola, jeans trouser, Mercedes-Benz etc).

According to Arens, Weigold and Arens (2008,p. 59), most people prefer Coca-Cola to some other soft drinks because "in the mind of the consumer, advertising has given the Coca-Cola brand an added value". Not necessarily because the product is functionally better. The scholars point out that in the mid-1960s, a famous psychologist, named Ernest Dichter, asserted that a product's image, created in part by advertising and promotion, is an inherent feature of the product itself. They add that subsequent studies showed that while an advertisement may not address a product's quality directly, the positive image conveyed by advertising may imply quality. Moreover, by simply making the products better known, advertising can make the product more desirable to the consumer. In these ways, advertising adds value to the brand, according to them.

\section{Theoretical Framework}

The dynamics of advertising as a persuasive communication will be best explained and understood when located in relevant and specific theoretical underpinnings. Accordingly, this discussion adopts three theories, namely Abraham Maslow's theory of Motivation, the Uses and Gratifications theory and the Perception theory, as the foundations for analysis.

According to Abraham Maslow's theory of human motivation, cited in Ciboh (2002:26), human beings possess five basic needs which can be placed in a hierarchy such that as lower needs are satisfied, we lose interest and concentrate on satisfying needs at the next higher level which has become the most pressing. To this end, human needs have certain priorities and each level must be satisfied to some extent before the next one becomes dominant. Accordingly, as a buyer/consumer satisfies the need of one level, he/she is seen as being further motivated to buy/consume towards satisfying the needs of the next higher level. The five steps in the hierarchy, in ascending order, are:

a. Physiological needs: food, clothing, shelter etc

b. Safety needs: pension, health etc

c. Love needs: the need to belong and relate to others.

d. Esteem needs: craving for respect, recognition and appreciation.

e. Self-actualisation needs: people need to do what makes them fulfilled and what makes them feel good about themselves. They want to explore their potentials and challenge themselves.

This theory is relevant to the discussion because advertising tries to persuade or motivate people to act in response to the identified needs.

The uses and gratifications theory belongs to the indirect effect theory. It is ultimately concerned with what people do with the media instead of what the media do to the people. The assumption of this theory is that people influence the effect that the media have on them. Blumler, Katz and Gurevitch (1974) cited in Anaeto et al (2008:70) point out that people are not just passive receivers of media messages, but they actively influence the message effect. This is because they selectively choose, attend to, perceive and retain the media messages on the basis of their needs, beliefs and other factors.

According to Anaeto et al (2008:70), in the mass communication process, much initiative in linking need gratification and media choice lies with the audience members. The receivers determine what is going to be absorbed and do not allow the media to influence them otherwise. Accordingly, people use the media to their advantage more often than the media use them. The media compete with other sources of need satisfaction. Each individual has several needs and in response to these needs, he/she creates a wide range of choices to meet these needs. The stronger rival to media-based sources is face-to-face communication because it helps individuals 
cope most effectively with circumstances surrounding them. As a result, mass communication must compete strongly with non-media-related sources and help create a need for itself as well as find a proper balance between the two. The theory points out that since the recipients have enormous influence on the effect process, the focus is shifted from media production and transmission functions to the media consumption function. This theory is important to the discussion because the media are seen as having a very powerful or a magic bullet effect on their audiences, and the uses and gratifications theory is saying, contradictorily, that audiences influence the effect that media messages have on them, which limits the effectiveness of the message of an advertisement.

On the perception theory, Wells, Moriarty and Burnett (2006:104) say perception is the process by which we receive information through our five senses and assign meaning to it. If an advertisement is to be effective, it, first of all, has to get noticed. Everyday we are bombarded with stimuli - faces, conversations, buildings, advertisements, news - yet we actually notice only a small fraction. Why? The answer is perception.

Advertising creates visibility for a product or brand through exposure. Consumers respond by selecting messages to which they pay attention, a process called selective perception. The first step in perception is exposure. Exposure is primarily a media buying problem. First, the message has to be placed in a medium that your target audience listens to, watches, reads or sees. Therefore, exposure is an important requirement to perception. If your target audience never sees or hears the advertisement, or if he/she skips the page or changes the channel, no matter how great, timely or significant the message is, it will not be perceived. Selective exposure is the tendency of the audience to screen out most of the information to which it is exposed. Audiences are exposed to a tremendous number of stimuli day after day and it will be impossible to pay attention to all of them.

Accordingly, selective exposure leads to selective attention. If audiences are not interested, they will pay no attention and the repetitions will be wasted. There is also selective distortion, which describes the tendency of people to adapt information to personal meanings. Audiences tend to interpret information based on their mindsets or in a way that will support what they already believe in. Furthermore, we have selective retention, which says audiences tend to retain information that supports their attitudes and beliefs. According to Folarin (1998: 64), "we more accurately remember messages that are favourable to our self-image than messages that are unfavourable".

These perceptual factors imply that marketers or advertisers have to work hard to get their messages across. This explains why they employ so much drama and repetition in sending their messages to their target audiences, to compete for their attention.

\section{Is No Place Safe from Advertising?}

Hardly can one go all of a day or even pass by a busy street without seeing an advertisement. Assuming a consumer stays away from radio and television, avoids reading newspapers and magazines, shuts out online advertisements by simply staying unlinked, what about billboards, the giant wood, steel or electronic panels that confront one on highways and on busy streets? They litter major roads and deface landscapes. Outdoor advertising, which billboards represent, is the most public mass medium. Billboards cannot be turned off like television, radio or the Internet, and it is displayed 24 hours a day for all to see.

As a consumer wakes up to take cereals in the morning, the boxes have McDonald's advertisements on them. As a passenger takes urban buses, not only are the insides of buses packed with advertisements but a lot of buses and now covered in vinyl wrap advertisements that let riders see out of the windows but turn buses into gigantic rolling commercials. As a customer walks, there will be advertising kiosks on the way. In the United States, according to Baran (2002:40), taxi cabs too carry advertisements on their trunk. He adds that even restrooms on campuses have advertisements pasted on their walls. He discloses that ATM receipts, too, carry advertisements for brokerage firms.

As consumers, people are exposed to hundreds and may be even thousands of commercial messages everyday. They may appear in the forms of magazine advertisements, billboards, pre-movie commercials, web sites and publicity product exposure, or in the form of television/radio commercials, coupons, sales letters, event sponsorships, telemarketing (the business or practice of marketing goods or services by telephone), calls or emails. These are just a few of the many communication tools that companies and organisations use to initiate and maintain advertising. According to Baran (2002:348), the typical individual living in the United States will spend, more than one year of his or her life just watching television commercials. He also says the typical American sees 3,000 advertising messages a day, and more than 2 million advertisements by the time he or she is 25 years old. He adds that it is a rare moment when Americans are not in the audience of some advertising or commercial. According Baran, this is one of the many reasons advertisers have begun to place their messages in many venues beyond the traditional commercial media, hoping to draw attention. He explains that advertising content appearing in non-traditional venues is called ambient advertising (Baran, 2002, p. 497). 
Advertisements seem to be creeping into every available space, according to Dominick (2002: 379 ). Consider the following eight occurrences identified by him.

1. Radio Shack bought advertising space on the side of a solar-powered rover due to be launched to the moon in 2003.

2. Entire sides of buildings in New York City have been turned into huge billboards. Similarly, this happens in Nigeria's mega cities (Lagos, Abuja etc) and various state capitals where complete sides of high rise buildings have been turned into enormous billboards especially by telecommunication companies like MTN or Glo. Furthermore, since 2003, Nigerian politicians have devised the strategy of painting over private homes and buildings on highways connecting major cities, towns and villages in their party colours, complete with all kinds of political advertisements. Of course, they do this after the payment of a fee agreed upon by the owners of such buildings. In rocky Plateau state, political messages are even splashed, sprayed or painted on boulders and rocks on major highways.

3. Banner-toting airplanes now regularly fly over crowds at major sporting events.

4. The media laboratory at the Massachusetts Institute of Technology (MIT) has invented wearable video. A leather jacket equipped with an ultra-thin video screen in the back shows commercials as the wearer walks around.

5. A company in San Francisco pays car owners a monthly fee in return for painting advertising on the sides of their cars. In Nigeria too, mass transit buses have advertisements painted on their sides for a fee. This can be seen most frequently on the Abuja Mass Transit buses plying roads in the Federal Capital Territory, and on commercial buses from the east (Ekene Dili Chukwu transport, the Young Shall Grow etc) travelling around the country.

6. A couple in Pennsylvania sold advertising space on their wedding invitations and thank-you notes to help pay for the ceremony.

7. In New Mexico, a company paid to have its advertising slogan painted on the sides of cows that stood by the highway.

8. A Mexican restaurant in San Francisco offered a free lunch for life to anybody who had the restaurant's logo tattooed on a body part. Forty people accepted the offer and got tattooed. (If they all showed up every day for an $\$ 8$ lunch for the next ten years it would cost the restaurant more than $\$ 1$ million).

There are a lot of advertisements and a lot of advertisers. Accordingly commercial messages are increasingly hurled at consumers in many unusual places. Baran (2002:338) says in the United States, many public schools sell advertising space on their walls and lunch menus. Police cars in Indiana carry advertisements on their trunks. Some golf courses sell advertisements at the bottom of the plastic cup that sits in the holes. Skatertizers, in-line skaters who earn as much as \$40 an hour for wearing a light weight, flat-screen television monitor around their necks that displays video taped commercials, are appearing in many cities. The television network, American Broadcasting Corporation (ABC), installs motion sensor-activated promotional advertisements above urinals in men's rooms that advertise its shows as users do their business. Several companies, among them FreeCar.com and Autowraps.com, offer various inducements to drivers to turn their cars into vinyl-wrapped moving advertisements. A New Jersey company sculpts clients' logos into fresh sand so that their advertisement greets morning beachgoers. Sports stadia now carry sponsors' names - Fly Emirates Airline (at Arsenal's London stadium); AIG Insurance (at Manchester United's Old Trafford) etc. In supermarkets, the shopping baskets have advertisements posted to the sides. Americans see advertisements on door hangers, in the mail, behind the batter at a basket ball game, on basketball backboards in city parks, on suspended video monitors as people wait in line at the amusement park. Americans hear advertisements even when they are on hold on the telephone. According to Baran (2007:339), only public protest halted US Department of the Interior's plans to have corporate advertising "sponsor" individual national parks in 1996.

Bovee and Arens (1983, p. 54), observe that "one of the most common complaints about advertising is simply that there is too much of it". They add that in US, consumer organisations protest "billboard blight" on the country's highways. Local politicians criticise "sign pollution" in their communities. The authors further say advertisements reach people in cars, elevators, parking lots, hotel lobbies and in their homes over the radio and on television, in newspapers and magazines, and through the mail. According to them, daily, people are awash in a sea of commercials and advertisements which can make life less pleasant than it might otherwise be.

Advertising professionals are eager to get their Messages noticed. Rodman (2006: 404) discloses that a 2004 study conducted by a major marketing research firm reveals that 61 percent of consumers believe that advertising is "out of control". In addition, 60 percent said they felt "much more" negative about advertising than they did a few years ago. The main reason the customers felt negatively about advertising, according to Rodman, is that there is just so much of it. He notes that 65 percent of an average newspaper is advertising, and newspapers get around 75 percent of their income from advertisements. He adds that half of an average magazine is advertising, and magazines pull in 50 percent of their income there. 
Furthermore, Rodman says most of the content and revenue of websites now come from advertising. According to him, commercial television and radio stations devote around 25 percent of their broadcast time to advertising (called "commercials" when aired on television or over the radio) and more than 30 percent during prime time, that period in the day $(7 \mathrm{pm}$ to $11 \mathrm{pm})$ when the highest possible number of viewers sits to watch television). $\mathrm{He}$ points out that broadcast income is derived almost entirely from commercials.

According to Rodman, it is becoming increasingly difficult to find spaces where advertising does not appear. He says advertisements for milk and movies have appeared on individual apples, bananas and oranges. Other advertisements appear on the street (literally on the street,) where people looking down can see them) on the floors of stores, on airport baggage carousels, and on the walls above urinals. Rodman further says advertisements talk to Americans from automated teller machines, and commercials appear on the televisionlike screens of gas pumps as a customer fills his tank. Rodman (2006: 405) tells more:

One company has even offered cash-strapped towns free police cars as long as it can put advertisements on the hoods and trunks. The offer has been accepted by 20 towns

\section{Discussion}

Advertising is sometimes called mass or non personal selling. Its usual purpose is to inform, persuade and remind customers about particular products, services and ideas. It is supposed to present the advertiser's story or product as effectively and as clearly as possible, without overstepping the bounds of honesty, truthfulness and good taste. Advertising is a big business. Arens, Weigold and Arens (2008, p. 58) reveal that "it accounts for approximately 1.1 percent of the US gross domestic product (GDP)". According to them, in relation to the total US economy, this percentage is small; but it is higher than in most countries. The authors point out that it amounts to a spending level of $\$ 567.79$ for every person in the country - the highest per capita in spending in the world. As Marcel Blenstein-Blanchet, the father of modern French advertising, pointed out (quoted in Arens et al 2008, p. 58) it is no coincidence that the level of advertising investment in a country is directly proportional to its standard of living.

Similarly, Packard (1957:1) observes that "Americans have become the most manipulated people, through advertising, in the world". He adds that advertising is a strange and rather exotic new area of modem life. According to him, it is about the way many people are being influenced and manipulated - far more than they realise - in the patterns of their everyday lives. Large scale efforts are being made, often with impressive success, to channel consumers' unthinking habits, their purchasing decision and their thought processes by the use of insights gleaned from psychiatry and the social sciences. Packard further says typically, these efforts take place beneath their level of awareness, so that the appeals which move them are often, in a sense, 'hidden'.

There is no doubt that we live in an over-communicated society. There are so many products from which to choose. For example, the average supermarket brims with thousands of items waiting to be sold. In a highly competitive society, goods must move for business people to survive. Therefore, companies must shout to be heard, and advertising is their megaphone. Outpouring of goods the economy is bestowing on people requires mass market. Accordingly, advertisers persuade us to step up our consumption.

Consumers' tolerance of advertising in the print media seems to be greater than in the broadcast media. Readers can simply turn the pages and ignore the advertisement if they so desire. Broadcast media tend to be more intrusive and therefore receive greater criticism. As Hanson (2005: 315) notes, when critics complain that there are too many commercials on television, few would be quicker to agree than advertising agencies and their clients. According Hanson (2005:315), they are very concerned about the huge number of commercials and other messages - collectively referred to as clutter - that compete for consumer attention between programmes on radio and television.

Hanson explains that advertisers dislike clutter because the more advertisements and non-programme messages there are on television, the less attention viewers will pay to any given message. He adds that a study conducted by the Cable Television Advertising Bureau found that viewers are much more likely to remember the first advertisement in a group (called a pod) than the fourth or fifth. He further says the clutter problem is not limited to television. According to him, each day, the average American adult is exposed to 150 advertisements in one form or another.

Hanson further says according to a study commissioned by advertising agencies and their client, clutter is reaching record levels. He reveals that in 2000, network television averaged 16: 43 minutes of clutter per hour during prime time and 20:53 minutes during the day. For this study, clutter was defined as anything that was not part of the programme itself: advertisements, public service announcements, network promotions, credits for the programme, and other gaps between programmes. Hanson adds that despite the problems of higher clutter, lower-rated network programmes, and increasing cost per thousand (CPM) rates, networks continue to sell advertising time, and advertising experts say that clutter won't disappear until clients stop buying time from the networks. 
Hanson observes that breaking through the clutter is a continuing challenge for advertisers, who have come up with a variety of solutions to the problem. Tyre maker, Goodyear, breaks through the clutter by putting its message on the Goodyear blimp (a non rigid, floating aircraft without wings, bearing the Goodyear sign and message). Drug companies fight clutter by using celebrities like former Senator Bob Dole, model Lauren Hutton, and National Football League (NFL) coach Dan Reeves to market medications that deal with controversial topics like impotence, hair loss, incontinence (lack of ability to control the bladder or bowels), and loss of sex drive. Of course, when all the companies are using celebrities, they have to start cutting through the clutter all over again.

In the new world of multimedia, multi-channel, multi-option communication, advertising has become omnipresent. It is everywhere, from the tidal wave of mailings and catalogues to the intrusion of telemarketing. But on television, Roman and Maas (2005:25) say viewers zap commercials with their remotes. Zapping is a device that pauses till the commercial is over. There are also other schemes called zipping (fast forwarding) and grazing (searching other channels for greener pastures - better programmes). New technologies have the power to change the way we watch television -and perhaps avoid watching commercials. Now, the digital video recorder enables consumers to zoom by television commercials.

Still, on television, advertisers influence entertainment programming through product placement, defined by Rodman $(2006: 174)$ as "the inclusion of a product in a movie for marketing purposes". According to him, in recent years, consumer goods companies have made wide use of this technique. Product placement serves as a type of promotional tie-in (a consumer product built around movie characters) as well as an additional source of revenue for the movie studio. Rodman explains that sometimes advertisers pay the studios outright for product placement, but often they merely arrange to promote the movies. For example, in the 2001 movie, Crocodile Dundee in Los Angels, the title character takes a friend to a Wendy's fast-food outlet, telling him it's "someplace really special". Wendy's did not pay for the placement but instead agreed to promote the film on its tray liners and in radio commercials.

Rodman says for years, television executives have been concerned about viewers skipping commercials. Commercial breaks have always signalled viewers to run to the bathroom, get a snack or make a phone call. The avoidance of commercials was heightened, according to him, by a succession of technological devices including remote controls, video tape recorders, and most recently digital devices such as TiVo that can automatically Jump advertisements. Consequently, many industry professionals feel that their only recourse is to make commercials part of the programming itself. That is why viewers will see sitcom (a situation comedy) characters occasionally stopping to extol the virtues of a breakfast cereal or characters in police dramas stopping to talk in front large billboards.

Rodman further points out that reality programmes have been especially ripe for product placement. Sears, for example, had a product placement deal with the American Broadcasting Corporation (ABC) for the broadcaster's programme, Extreme Makeover: Home Edition. The show has included not just the use of Sears products but also several scenes of Sears trucks delivering merchandise, plumbers and other workers from Sears home-improvement services making repairs, and visits to Sears stores by the show's makeover team cast.

Rodman notes that critics of product placement believe that the practice confuses viewers by masking the sponsor's role in determining the content of entertainment programming. According to him, one critic called the practice "an affront to basic honesty". He adds that critics also insist that product placement defies the very definition of advertising, which includes the idea of an identified sponsor.

\section{Conclusion}

Advertising is a remarkable field. It even looks to be inevitable. Clearly, it satisfies the need to get noticed. Advertising is multifaceted - it is a business, a marketing tool, a dynamic, hybrid discipline that employs numerous elements of the arts and social sciences. It is also a creative business and the inventiveness of people in it never ceases to amaze, as advertisers continue to thrust messages into our noses, eyes and ears.

All over, advertising is everywhere; continuously troubling customers, exhausting and wearing them out, in a sweeping attempt to win them over. All the intrusiveness means it is excessive and offensive. Many consumers feel irritated and tormented enough by advertising's unceasing constancy as to wish to escape the storm by tuning out. For print media advertisements, readers simply turn the pages. For television commercials, viewers easily and openly zap, zip, zoom or even graze.

\section{Recommendations}

1. Considering that many marketers are experiencing lower response rates to their campaigns as a result of filters and other avoidance techniques, the Advertising Practitioners' Council of Nigeria (APCON) should be empowered to regulate the exposure of advertisements to audiences. As philosophers say, less is more. Accordingly, if audiences are not inundated with advertisements, the few they are exposed to are more likely to be effective. 
2. Viral marketing, which according to Wells, Moriarty and Burnett (2006:13) relies on consumers to pass messages about products among themselves - typically through e-mail - and consumers' direct involvement in product making are possible solutions to the dilemma.

\section{References}

[1]. Agee, W.K; Ault, P.H \& Emery, E. (1982) Perspective on Mass Communications, New York: Harper \& Row publishers.

[2]. American Heritage Dictionary of the English Language (2000), Boston: Houghton Mifflin Company.

[3]. Anaeto, S., Onabajo, O.S. \& Osifeso, J.B. (2008) Models and Theories of Communication, Maryland: African Renaissance Books Incorporated.

[4]. Arens, W.F; Weigold, M.F. \& Arens C. (2008) Contemporary Advertising, Boston: McGraw-Hill/Irwin.

[5]. Azzaro, M. (2004) Strategic Media Decisions, Chicago: The Copy Workshop.

[6]. Baran, S.J. (2002) Introduction to Mass Communication: Media Literacy and Culture, Boston: McGraw-Hill.

[7]. Bovee, C.L. \& Arens, W.F. (1983) Contemporary Advertising,Boston: McGraw-Hill.

[8]. Ciboh, R. (2002) Print Media Management Theories and Methods, Makurdi: Abogom Press

[9]. Dominck, J.R. (2002) The Dynamics of Mass Communication: Media in the Digital Age, Boston: McGraw-Hill.

[10]. Folarin, B. (1998) Theories of Mass Communication: An Introductory Text, Ibadan: Stirling-Horden Publishers.

[11]. Ginn, S.B. (1995) Language Arts Handbook, Ohio: Multi-Source.

[12]. Hanson, R.E. (2005) Mass Communication: Living in a Media World, Boston: McGraw-Hill.

[13]. Okunna, C.S. (1994) Introduction to Mass Communication, Enugu: New Generation Books.

[14]. Packard, V. (1957) The Hidden PersuadersLondon: Penguin Books Ltd.

[15]. Rodman, G. (2006) Mass Media in a Changing World: History, Industry, Controversy Boston: McGraw-Hill.

[16]. Roman, K. \& Maas, J. (2005) How to Advertise, London: Kogan page Limited.

[17]. "Top Advertising Agencies Shaping Business in 2009", in THISDAY newspaper, February 15, 2009. Lagos: Leaders and Company.

[18]. Wells, W., Moriarty, S. \& Burnett, J. (2006) Advertising: Principles \& Practice, New Jersey: Pearson/Prentice-Hall 